\title{
A method for determining and exploring the distribution of organic matters and hardness salts in natural waters
}

\author{
Suren Sargsyan ${ }^{1}$
}

Received: 8 March 2016/ Accepted: 28 November 2016/Published online: 10 December 2016

(C) The Author(s) 2016. This article is published with open access at Springerlink.com

\begin{abstract}
A question regarding how organic matters in water are associated with hardness salts hasn't been completely studied. For partially clarifying this question, a water fractional separation and investigation method has been recommended. The experiments carried out by the recommended method showed that the dynamics of the distribution of total hardness and permanganate oxidation values in the fractions of frozen and melted water samples coincided completely based on which it has been concluded that organic matters in natural waters are associated with hardness salts and always distributed in this form. All these findings are useful information for the deep study of macro- and microelements in water.
\end{abstract}

Keywords Water freezing-melting method · Fractional separation of water impurities - Total hardness .

Permanganate oxidation - Hardness salt and organic matter distribution

\section{Introduction}

It's known that for the concentration of impurities in waters, the water freezing method is applied which ensures the distribution of impurities in the different phases of ice (Abhishek et al. 2011; Halde 1980; Makoto et al. 1994; Shahnaz and Harold 1991; Stadnik and Dedkov 1981; Ye et al. 2014). During an increase in the temperature, the sequence of the

Suren Sargsyan

Sarsur@bk.ru

1 Institute of Hydroecology and Ichthyology of the Scientific Center of Zoology and Hydroecology of NAS RA, Paruyr Sevak St. 7, 0014 Yerevan, Armenia separation of salts in ice is determined by their eutectic temperature and mixture composition. In the ice melting process, the freezing curve is completely repeated but in reverse direction (http://chem21.info/info/1452163/). For the investigation of valuable information in the process of the melting of frozen water samples, it's necessary to create stable conditions for ensuring the high reproducibility of experiments. Therefore, the first aim of the work was to investigate and develop conditions ensuring the high reproducibility of the results in the process of the freezing-melting of water samples. It should be mentioned that the question regarding how organic matter is associated with hardness salts hasn't been completely studied, and on the other hand, it's difficult to investigate microelements which is conditioned not only by their low concentration but also by the unclarity of their existence form in mixture. All of this makes difficulties for the investigations of their migration and chemical processes in water. It's known that the migration of many heavy metals occurs in a suspended state and at the same time, most of metals (firstly di- and trivalent metals) can form dissolved organic complexes with humic and fulvic acids (Kondrateva et al. 2011; Linnik and Nabivanec 1986; Ostrovskaya et al. 2008; Sieliechi et al. 2012; Wang-Wang et al. 2014). For partially clarifying the aforementioned questions and particularly how organic matter is associated with hardness salts, organic matter and water hardness parameters in water samples before and after the freezing-melting process were simultaneously investigated.

\section{Materials and methods}

The water samples were taken from the 8 observation sites in the Lake Sevan basin (Argichi river source, midstream and mouth; Karchaghbyur and Vardenis rivers' source and 
mouth; Gavaraget river mouth) and a natural drinking water source in July, 2014. The water samples were poured into plastic bottles $\left(\begin{array}{ll}1 & 1\end{array}\right)$ having smooth walls. The volume of water sample did not exceed $1 / 4$ of bottle volume. The bottles were placed in the refrigerator ice-chamber in horizontal position to allow freezing. This technique ensures the high reproducibility of results. In our experiments, the volume of water was $250 \mathrm{ml}$ because a melting dynamics of the water samples of a volume of 50, 100, 200 and $250 \mathrm{ml}$ was deeply studied, and the reproducibility of results for each volume is the same.

The other advantage of freezing in horizontal position against freezing in vertical position is, that due to larger contact surface area, freezing and melting process of a water sample in a bottle in horizontal position occurs faster than that in vertical position (Sargsyan 2015).

Completely frozen water samples were taken from the refrigerator ice-chamber, and the bottles were placed in vertically inverted position (bottleneck was turned down), and were fastened to the top of a measuring cylinder. Ice melted to water and was gradually collected into the measuring cylinder at room temperature $\left(20 \pm 2{ }^{\circ} \mathrm{C}\right)$. Melting process acceleration on account of an increase in temperature is undesirable, as it distorts highlighted difference between the investigated parameters in fractions. After the beginning of melting process, the frozen and melted waters were separated into 5 consecutive fractions (in separate tubes) having equal volumes. The melted water sample's volume was $250 \mathrm{ml}$, the first $50 \mathrm{ml}$ of melted water was considered as the I fraction, the second $50 \mathrm{ml}$ of melted water-the II fraction, the third $50 \mathrm{ml}$ of melted water-the III fraction, the fourth $50 \mathrm{ml}$ of melted waterIV fraction and the last $50 \mathrm{ml}$ of melted water-the $\mathrm{V}$ fraction (Sargsyan 2015).

Permanganate oxidation (PO) and total hardness (TH) analyses in 5 melted water fractions obtained by the abovementioned method were performed. PO value was determined by the Kubel method, and $\mathrm{TH}$ was investigated by the 2 methods: complexometric and salt settling methods (Lure 1971, 1973; Sargsyan 2014). The physical density of the water samples was measured by an aerometer.

However, a question regarding why measurements should be performed in exactly 5 consecutive fractions having equal volumes is posed. In different natural waters, the dynamics of the changes of the mentioned parameters was multiply investigated in 3-20 equal fractions. The main results of the previous study have indicated that clear and strongly highlighted difference between these parameters is observed in case of the separation of frozen and melted water into exactly 5 consecutive fractions (Sargsyan 2015). Certainly, based on experimental purposes and specific features of water, any quantity of fractions can be considered, nevertheless, it should be experimentally grounded in advance.

\section{Results and discussion}

The results of the study showed that due to the freezing and fractional melting process, hardness salts were concentrated by 1.30 times (the III fraction of the water sample taken from the Vardenis river mouth) to 2.40 times (the III fraction of the water sample taken from the Karchaghbyur river source) compared to the same parameter values in the water samples before the freezing-melting process. In the other cases, hardness salts were maximally concentrated by averagely 1.80 times which was mainly distributed in the I fraction of the water sample taken from the Argichi river mouth, the II fraction of the water samples collected from the Karchaghbyur river mouth and the III fraction of the other water samples (Fig. 1). The concentration of hardness salts in the different fractions of the frozen and melted water samples was apparently conditioned by dissimilar qualitative compositions of these salts in different water samples.

The results of the study of PO values (organic matter content) in the frozen and melted water samples showed that, compared to the content of organic matters in the water samples before freezing-melting process, the maximal concentration of organic matters (1.88 times) in the frozen and melted water samples was registered in the III fraction of the water samples collected from the Argichi river midstream, nevertheless, the minimal concentration (1.1 times) was observed in the III fraction of the water sample taken from the Vardenis river source. In the other frozen and melted water samples, organic matters were maximally concentrated by averagely 1.46 times. The joint observation of $\mathrm{TH}$ and $\mathrm{PO}$ values posed a very important and common regularity: maximal $\mathrm{TH}$ values in the fractions not only coincided with the maximal PO values but also a coincidence of the dynamics of the distribution of their values according to the fractions of the frozen and melted water samples was observed (Fig. 1).

All of this allows to conclude that organic matters in natural waters are associated with hardness salts probably in the form of complex compound. For the scientific grounding of this conclusion, it was necessary to solve the following question: how would organic matters be distributed in the same experimental conditions in case of the absence of hardness salts? For removing the hardness salts from the same output water samples, water hardness was determined by the chemical method based on the settling of salts (Sargsyan 2014). Then, the desalted waters were frozen and melted to undergo such a fractional analysis as it was done in the non-desalted water samples. In case of 
Fig. 1 The dynamics of $\mathrm{PO}$ (stippled line) and $\mathrm{TH}$ (uninterrupted line) values in the frozen and melted water samples according to the fractions (a-Karchaghbyur river source; $\mathbf{b}$-Karchaghbyur river mouth; $\mathbf{c}-$ Vardenis river source; $\mathbf{d}-$ Vardenis river mouth; e-Argichi river source; f-Argichi river midstream; $\mathbf{g}$ Argichi river mouth; $\mathbf{h}-$

Gavaraget river mouth; $\mathbf{i}-$ natural source; $\mathrm{O}-\mathrm{PO}$ values in the water samples before freezing-melting process; $\mathrm{TH}$ values in the water samples before freezing-melting process)
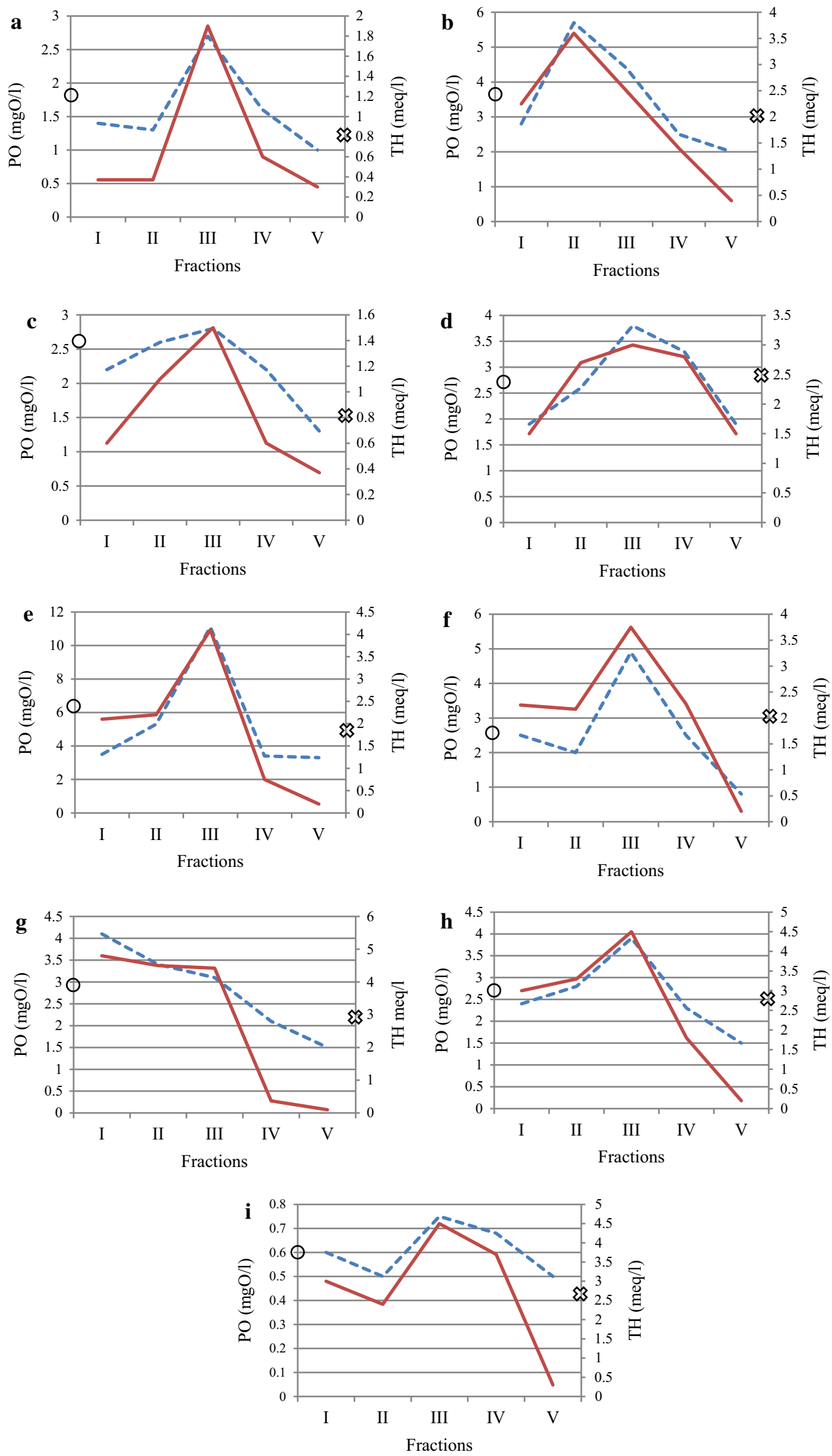
Fig. 2 The dynamics of PO values in the previously desalted, frozen and melted water samples according to the fractions (a-Karchaghbyur river source; $\mathbf{b}$-Karchaghbyur river mouth; $\mathbf{c}-$ Vardenis river source; $\mathbf{d}-$ Vardenis river mouth; e-Argichi river source; f-Argichi river midstream; $\mathbf{g}$ Argichi river mouth; $\mathbf{h}-$

Gavaraget river mouth; $\mathbf{i}-$ natural source)
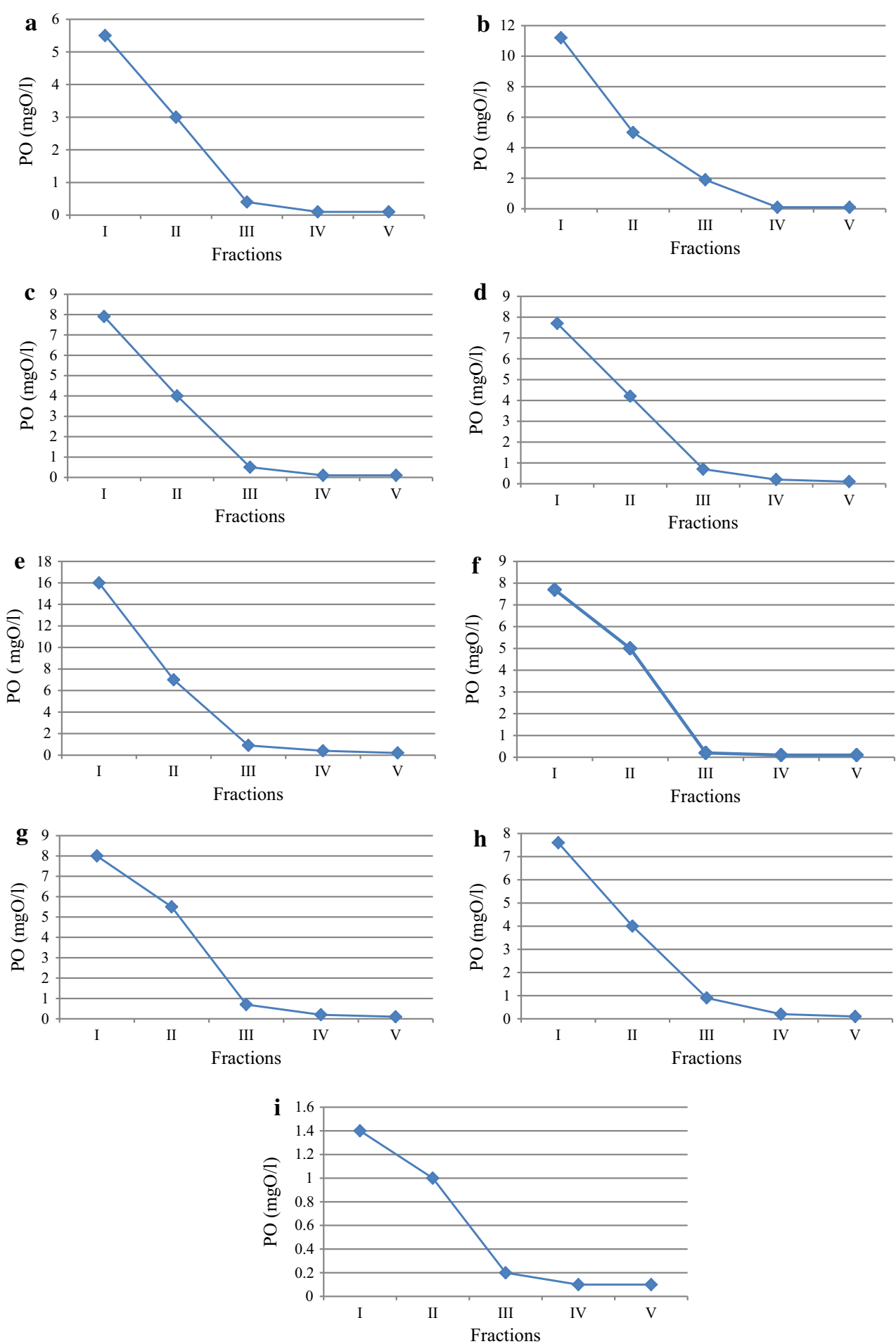

the absence of hardness salts, organic matters were mainly maximally concentrated in the I fraction of the frozen and melted water samples and significantly less concentrated in the II fraction (Fig. 2). The existence of low organic matter content in the II fraction may have been the result of residual organic matter washed out of ice and the presence of ions not being conditioned by hardness salts. The measurements of physical density $(\alpha)$ of the fractions of the frozen and melted water samples recorded the following mean values: $\alpha=996 \mathrm{~kg} / \mathrm{m}^{3}$ in the I fraction; $\alpha=994 \mathrm{~kg} /$ $\mathrm{m}^{3}$ in the II fraction; $\alpha=993 \mathrm{~kg} / \mathrm{m}^{3}$ in the III, IV and V fractions. The results of the experiments showed that in the conditions of the absence of hardness salts, organic matters in the fractions of the frozen and melted water samples 


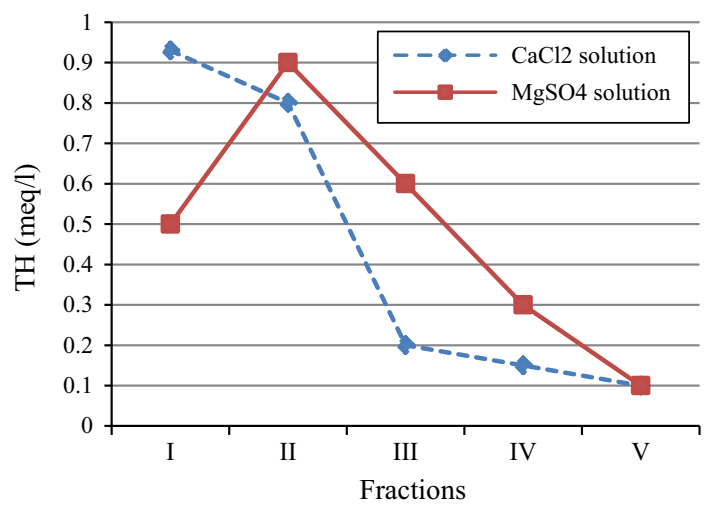

Fig. 3 The distribution of $\mathrm{TH}$ values in the frozen and melted solutions of $\mathrm{CaCl}_{2}$ and $\mathrm{MgSO}_{4}$ (in the conditions of the absence of organic matters) according to the fractions

were mainly distributed according to high physical density value which was the result of the concentration of water impurities in the freezing-melting process (Fig. 2).

Thus, the study of organic matter distribution in the frozen and melted water samples in the conditions of the absence of hardness salts has confirmed the abovementioned conclusion that organic matters in water are associated with hardness salts. This is apparently conditioned by the fact that many hydroxides of metals in water exist in the form of colloidal compounds, and organic matter adsorption on colloid surface probably occurs as a result of which they obtain high stability (http://all-about-water.ru/ chemical-composition.php). Thus, due to the movement of salts in the frozen and melted water samples, organic matters being associated with salts in the form of such a complex compound were moved to the same fractions. As the result, the complete coincidence of the distribution of hardness salt and existing organic matter concentrations according to the fractions was observed (Fig. 1).

As the hardness of natural waters is mainly conditioned by the existence of $\mathrm{Ca}^{2+}$ and $\mathrm{Mg}^{2+}$ ions, it was interesting to separately observe the fractional distribution of these salts by the aforementioned method. For this purpose, the dynamics of the distribution of hardness salts in the 5 fractions of $0.04 \% \mathrm{CaCl}_{2}$ and $\mathrm{MgSO}_{4}$ solutions after freezing-melting process (in the conditions of the absence of organic matters) was separately investigated and is presented in Fig. 3. The maximal quantity of $\mathrm{Ca}^{2+}$ ions was concentrated in the I fraction, and little less quantity was concentrated in the II fraction. The maximal quantity of $\mathrm{Mg}^{2+}$ ions was registered in the II fraction, and little less quantity was recorded in the III fraction. In the other fractions, decreasing dynamics for both $\mathrm{Ca}^{2+}$ and $\mathrm{Mg}^{2+}$ ions was observed which was the result of the washing of residual quantities in ice melting process (Fig. 3). The results of the study have shown that by applying the method of the fractional separation of water samples, it becomes possible not only to concentrate salts but also to implement their partial separation into different fractions. This is a great advantage in the deep study of macro- and microelements.

\section{Conclusions}

A water fractional separation method, which allows to concentrate and partially separate dissolved impurities into different fractions, has been recommended. The dynamics of the distribution of $\mathrm{TH}$ and $\mathrm{PO}$ values in the fractions of frozen and melted water samples coincided completely which has indicated that organic matters in natural waters are always associated with hardness salts apparently in the form of complex compound, and they migrate to different fractions in this conditions.

Open Access This article is distributed under the terms of the Creative Commons Attribution 4.0 International License (http:// creativecommons.org/licenses/by/4.0/), which permits unrestricted use, distribution, and reproduction in any medium, provided you give appropriate credit to the original author(s) and the source, provide a link to the Creative Commons license, and indicate if changes were made.

\section{References}

Abhishek BS, Ranjit RD, Siddharth KJ (2011) Freeze concentration of sugarcane juice in a jaggery making process-modeling. Int $\mathbf{J}$ Model Optim 1:118-121

Halde R (1980) Concentration of impurities by progressive freezing. Water Res 14:575-580. doi:10.1016/0043-1354(80)90115-3

Kondrateva LM, Shunkova NN, Andreeva DV (2011) Effect of heavy metal ions on the structure of bacteriobenthos from different habitats in the Amur river. Vladimir Ya. Levanidov's Biennial Memorial Meetings 5:239-246 (in Russian)

Linnik PN, Nabivanec BI (1986) Forms of the migration of metals in fresh surface waters. Gidrometeoizdat, Leningrad (in Russian)

Lure UU (ed) (1971) Uniform methods for the analysis of waters. Khimiya, Moscow (in Russian)

Lure UU (ed) (1973) Uniform methods for the analysis of waters. Khimiya, Moscow (in Russian)

Makoto S, Masato S, Kei-ichi I, Yoshikazu F, Satoshi I, Kenji W (1994) Freezing and eutectic points of an aqueous amino acid solution containing ethanol, and the effect of ethanol addition on the freeze concentration process. Biosci Biotechnol Biochem 58:836-838. doi:10.1271/bbb.58.836

Ostrovskaya EV, Brekhovskikh VF, Volkova ZV, Monakhov SK, Kurapov AA, Kocharyan AG (2008) Heavy metals in the system "Volga Delta-North Caspian". South Rus: Ecol Dev 4:156-163 (in Russian)

Sargsyan SA (2014) A method for determining water hardness. Patent of RA, № 2823 A (in Armenian)

Sargsyan SA (2015) A method for fractional separation of water according to the density of organic matters and hardness salts and a method for removing organic matters and hardness salts from water. Patent of RA, № AM20150068 (in Armenian)

Shahnaz I, Harold FH (1991) Evaluation of a freeze-concentration technique for enrichment of natural organic substances in water. Anal Lett 24:1035-1045. doi:10.1080/00032719108054372 
Sieliechi JM, Lartiges BS, Ndi SK, Kamga R, Kayem GJ (2012) Mobilisation of heavy metals from natural pozzolan by humic acid: implications for water and environment. Int $\mathbf{J}$ Environ Prot 2:11-15

Stadnik AS, Dedkov UM (1981) Freezing as a method for the concentration of impurities in waters. Water Chem Technol 3:227-233 (in Russian)

Wang-Wang T, Guang-Ming Z, Ji-Lai G, Jie L, Piao X, Chang Z, Bin-Bin H (2014) Impact of humic/fulvic acid on the removal of heavy metals from aqueous solutions using nanomaterials: a review. Sci Total Environ 468-469:1014-1027. doi:10.1016/j. scitotenv.2013.09.044

Ye X, Zhi-Gang H, Fan Y, Xian-Guo L (2014) The dynamics of soil moisture and salinity after using saline water freezing-melting combined with flue gas desulfurization gypsum. Polish J Environ Stud 23:1763-1772 